\title{
Isu Perkawinan Dan Kelas Sosial Dalam Metropop Melbourne (Wedding) Marathon Karya Almira Bastari: Kritik Sastra Feminis
}

\author{
Tania Intan \\ tania.intan@unpad.ac.id \\ Fakultas Ilmu Budaya, Universitas Padjadjaran
}

\begin{abstract}
Abstrak. Penelitian ini bertujuan untuk menguraikan permasalahan tentang perkawinan dan kelas sosial yang ditampilkan dalam novel metropop Melbourne (Wedding) Marathon karya Almira Bastari. Metode yang digunakan dalam penelitian ini adalah deskriptif-kualitatif. Data berupa kata, frasa, dan kalimat dikumpulkan dengan teknik simak-catat. Data kemudian diklasifikasi sesuai dengan permasalahan penelitian, dan dikaji dengan pendekatan struktural dan kajian sastra feminis. Landasan teoretis yang digunakan di antaranya adalah dari Humm, Foucault, dan Priyatna. Hasil penelitian menunjukkan bahwa sesuai dengan kriteria metropop, seluruh elemen naratif dalam novel yang dikaji mendukung ide tentang percintaan dan perkawinan dengan latar urban. Sekalipun berada dalam situasi modern dan berkarakter mandiri, perkawinan masih didambakan oleh perempuan dengan harapan menjadi lembaga yang mengusung kesetaraan gender. Isu kelas menjadi hambatan dalam relasi percintaan namun dapat diatasi berkat penolakan perempuan atas wacana penguasaan.
\end{abstract}

Kata Kunci: perkawinan, metropop, kelas sosial, kajian sastra feminis

\section{Pendahuluan}

Dalam konteks budaya Timur, status menikah merupakan hal yang penting bagi seorang perempuan. Sebagai dampaknya, perempuan yang telah 'cukup umur' namun belum menikah kerap mendapatkan label dari masyarakat sebagai 'perawan tua', 'tidak laku', 'pemilih', atau 'suka jual mahal' (Mami \& Suharman, 2015: 216). Hal ini terjadi karena perkawinan, dalam perspektif feminis, merupakan institusi yang secara tradisional menyediakan identitas sosial bagi perempuan. Perkawinan adalah tempat kategori gender direproduksi, tempat pembagian kerja secara seksual dan subordinasi perempuan, serta model institusi sosial lainnya mengenai norma seksual (Humm: 2007: 266). Realita bahwa tubuh perempuan digambarkan dan diberi identitas oleh dunia patriarki, dijelaskan Adji dkk. (2009: 18), membuat perempuan tidak dapat memberi identitas untuk dirinya sendiri. Laki-laki menjadi ukuran untuk mendefinisikan dan menentukan takdir perempuan, bukan perempuan yang diukur atas kualitas yang dimilikinya sendiri.

Dalam pandangan Priyatna (2018: 167), perempuan dianggap tidak utuh bila belum memiliki pasangan [heteroseksual]. Sebagaimana di dunia nyata, di dalam novel pun, perempuan sering digambarkan 'belum lengkap' hingga tokoh tersebut dipersatukan dengan tokoh laki-laki yang digambarkan sebagai sosok ideal baginya, yang mencintai dan dicintainya. Priyatna (2018: 11) juga berargumentasi bahwa laki-laki yang didefinisikan sebagai the right person, tidak pernah memenuhi kriteria "penyayang, penuh perhatian, dan kategori klise lainnya." The right person 'orang yang tepat' bukan orang yang nyaman dengan posisi dominan, dan bukan pula yang merasa nyaman dengan posisi subordinat. Orang yang tepat adalah orang yang bersedia untuk berkompromi dengan kebutuhan-kebutuhan dan situasi yang ia hadapi bersama pasangannya. Oleh karena itulah, wacana perkawinan [seharusnya] tidak menjadi wacana penguasaan. 
Teori konflik Marxis dapat digunakan dalam kajian gender untuk menjelaskan peran perempuan dan laki-laki, yang dibangun dengan asumsi dasar bahwa perbedaan dan ketimpangan gender tidak disebabkan oleh perbedaan biologis, tetapi merupakan bagian dari penindasan oleh kelas yang berkuasa (lebih kuat) terhadap kelas yang lemah, yang kemudian diterapkan dalam konsep keluarga. Hubungan di antara laki-laki dan perempuan tidak ubahnya seperti hubungan borjuis dan proletar, tuan dan hamba, pemeras dan yang diperas (Umar, 1999: 61). Dengan demikian, ketimpangan peran gender dalam masyarakat terjadi bukan merupakan pemberian Tuhan (divine creation), melainkan karena konstruksi sosial.

Ketika memasuki kehidupan perkawinan, menurut Putri dan Lestari (2015: 72-75), perempuan dan laki-laki memiliki peran baru yang merupakan konsekuensi dari relasi tersebut. Ada banyak stigma yang dilekatkan oleh kaum feminis untuk menunjukkan ketimpangan hubungan di antara kedua pihak yang berada di dalam institusi perkawinan. Menurut Delphy (1977) yang dikutip Humm (2007: 266), perkawinan adalah kontrak kerja yang memungkinkan suami mendapatkan pekerjaan tanpa upah dari istrinya dengan model produksi domestik dan model eksploitasi dari struktur patriarkis. Demikian pula dengan maraknya kekerasan dalam rumah tangga terhadap perempuan oleh partner perkawinan mereka, yang diduga berasal dari prasangka dan kekuasaan laki-laki atas perempuan.

Di masa lalu, menurut Botkin, Weeks, \& Morris (2000) yang dikutip Putri dan Lestari (2015: 74), gaya hidup khas dari pasangan menikah digambarkan sebagai situasi ideal, yaitu masing-masing memiliki peran yang tidak tertulis dan menghasilkan keharmonisan perkawinan. Suami bertugas mencukupi kebutuhan istri dan keluarga, sementara istri bertanggung jawab mengurus rumah dan anak-anak. Seiring perkembangan zaman dan gaya hidup yang lebih modern, ada pergeseran peran gender dari tradisional menjadi egaliter, yang berarti perempuan dan lakilaki dipandang sama dalam semua domain.

Bagaimanapun juga, perkawinan tetap menjadi tujuan bagi kebanyakan perempuan, sebagaimana dinyatakan Heise (2012) dengan mengutip Cherlin, bahwa sekalipun angka perceraian meningkat, perkawinan "remains the most highly valued form of family life, the most prestigious way to life your life" "tetap merupakan nilai tertinggi dari kehidupan keluarga, jalan yang paling berharga untuk menjalani hidup Anda'. Perkawinan memang tidak pernah dianggap sebagai hal yang sederhana, karena masih banyak orang yang memandangnya sebagai hal yang sakral, luar biasa, dan hanya terjadi satu kali dalam seumur hidup. Perkawinan tidak hanya dipandang sebagai legalitas atas hubungan seksual di antara perempuan dan laki-laki, melainkan sebagai pemersatu dari dua latar keluarga yang terhubung.

Dalam perspektif gender, tuntutan untuk menikah jauh lebih berat pada perempuan daripada laki-laki. Kecenderungan budaya patriarkis pada konteks Indonesia telah membuat perempuan didorong untuk segera menjadi ibu dan istri dalam sebuah keluarga, agar ia dihargai sebagai anggota masyarakat sepenuhnya (Kumalasari, 2007). Perempuan dewasa yang memiliki status identitas lajang akan mengalami ancaman berupa evaluasi negatif atau stereotip tertentu dari masyarakat. Dengan kondisi tersebut, dapat dinyatakan bahwa perempuan rentan menjadi target stigma. Stigma, menurut Goffman yang dikutip Septiana \& Syafiq (2013: 74), adalah penilaian kualitas baik fisik, sosial atau personal yang membuat kelompok orang yang 
memilikinya dilabeli dengan identitas yang mendiskreditkan dan inferior. Stigma yang biasanya melekat pada perempuan dewasa lajang adalah kurang dapat mengemban tanggung jawab, kurang dewasa, dan kurang bisa bergaul (Conley \& Collins, 2002).

Kecenderungan menilai perkawinan sebagai urgensi dalam hidup perempuan terdeteksi hadir di dalam novel karya Almira Bastari yang berjudul Melbourne (Wedding) Marathon (2017). Kegelisahan berkepanjangan dialami tokoh perempuan, Sydney Deyanira, karena di usianya yang menjelang 25 tahun, ia belum juga menikah dan bahkan belum pernah berpacaran. Sebaliknya, ia merasa resah karena merasa harus menghadiri pesta pernikahan teman-temannya secara berturutturut hampir setiap akhir pekan. Pertemuannya dengan Anantha kemudian dapat membawanya ke jenjang perkawinan setelah melalui berbagai hambatan, termasuk perbedaan kelas sosial.

Novel Melbourne (Wedding) Marathon merupakan sebuah metropop, yaitu istilah yang dibuat PT Gramedia Utama Pustaka untuk menamai novel populer terbitannya (Fitriana, 2010: 8) dan sering disandingkan dengan urban lit dari Kensington Books. Metropop adalah novel yang selalu bercerita tentang percintaan, pekerjaan, dan gaya hidup masyarakat urban. Berbeda dengan chick lit, pada metropop, perempuan dan laki-laki dapat menjadi tokoh utama, dapat ditulis oleh perempuan dan laki-laki, serta dapat dibaca oleh perempuan dan laki-laki. Latar tempat selalu berada pada ruang metropolitan dengan kehidupan mapan dan gaya hidup glamor yang menyertai para tokohnya (Intan, dkk. 2019: 584-585).

Sebagai arena pertarungan ideologi, teks sastra dapat memuat kepentingan politis dan tendensi tertentu tentang relasi di antara perempuan dan laki-laki. Perspektif feminis menyaran pada realitas bahwa karya sastra merupakan sarana efektif untuk sosialisasi ideologi patriarkis dan model reading as woman 'membaca sebagai perempuan' diperlukan untuk mendekonstruksi pembacaan androsentris, terutama tentang perkawinan. Pelanggengan atas ideologi patriarkis tergambar misalnya pada berulangnya tema ketergesa-gesaan perempuan untuk menemukan jodoh dan menikah. Beberapa di antaranya adalah novel 30 Hari Mencari Cinta karya Nova Riyanti Yusuf, 90 Hari Mencari Suami karya Ken Terate, Otw Nikah karya Asma Nadia, dan Kebelet Nikah karya Anisa Hakim. Relasi pura-pura atau fake relationship pun bukan merupakan tema baru dalam dunia fiksi, seperti yang dapat ditemukan dalam novel Fake Relationship karya Evathink, Fake Boyfriend karya A. Vani, Risti dan Suami Bayaran karya Diganti Mawaddah, dan Miss Nerd Secret Pleasure karya Noismela. Kesenjangan kelas sosial di antara tokoh perempuan dan laki-laki pun dapat mengingatkan pembaca pada novel Crazy Rich Asian karya Kevin Kwan dan serial drama Meteor Garden.

Penelitian yang melibatkan isu perkawinan dalam karya sastra telah dilakukan di antaranya oleh Fahmi dan Arfiyanti (2020) yang mengkaji kesetaraan gender dalam novel Cinta Suci Zahrana karya Habiburrahman El-Shirazy. Temuan dari penelitian tersebut adalah ada kecenderungan pada perempuan lajang yang berpendidikan dan berkarier tinggi mendapat desakan untuk segera menikah. Hal ini terjadi karena kuatnya budaya patriarki yang memiliki kehendak untuk menempatkan perempuan [kembali] ke ranah domestik. Sebaliknya, laki-laki memiliki keleluasaan untuk melajang karena dianggap memiliki hak untuk memilih.

Kajian atas karya Almira Bastari telah dilakukan Anggraini dan Hayati (2019) yang menelaah novel Resign!, dan menemukan bahwa dalam karya tersebut dideskripsikan potret 
masyarakat urban. Sebagai penciri metropop, karakter urban ditunjukkan dengan adanya rekreasi, budaya hidup instan, gaya hidup individualis, dan penggunaan teknologi secara masif.

Dari hasil penelusuran yang dilakukan peneliti, diketahui bahwa sejauh ini novel Melbourne (Wedding) Marathon belum pernah diteliti secara ilmiah, sehingga terbuka celah untuk selanjutnya dilakukan penelitian. Untuk membatasi wilayah kajian, maka dirumuskan bahwa permasalahan dan tujuan dari penelitian ini adalah mengungkap permasalahan tentang perkawinan dan kelas sosial di dalam novel Melbourne (Wedding) Marathon karya Almira Bastari.

\section{Metode}

Metode yang digunakan dalam penelitian ini adalah deskriptif kualitatif. Data yang terdiri dari kata, frasa, dan kalimat dikumpulkan dengan teknik studi dokumentasi. Data kemudian dikaji melalui makna verbal dan konteks, dengan pendekatan struktural untuk membahas narasi percintaan dan kritik sastra feminis untuk mempelajari isu perkawinan dan kelas sosial.

Kritik sastra feminis digunakan karena teks yang ditelaah merupakan novel metropop yang ditulis perempuan, dibaca perempuan, dan membicarakan terutama tentang perempuan. Wiyatmi (2012: 11) mengutip Ruthven yang menyatakan bahwa kritik sastra feminis bersifat revolusioner karena memiliki tujuan menumbangkan wacana dominan yang diciptakan suara tradisional dan patriarkis. Wiyatmi (2012: 30) juga mengutip Showalter yang memaparkan dua jenis kritik sastra feminis, yaitu kritik yang melihat perempuan sebagai pembaca dan kritik yang melihat perempuan sebagai penulis. Untuk penelitian ini, akan digunakan kritik sastra yang melihat perempuan sebagai pembaca karena kritik ini berfokus pada citra dan stereotip perempuan dalam sastra, serta pengabaian dan kesalahpahaman tentang perempuan. Perempuan dalam karya sastra hampir selalu ditempatkan sebagai korban, bersifat sentimental dan memiliki kepekaan spiritual di bawah dominansi laki-laki (Djajanegara, 2003: 7).

Novel Melbourne (Wedding) Marathon adalah karya pertama Almira Bastari dan diterbitkan pertama kali pada bulan Juli 2017 oleh PT Gramedia Widiasarana Indonesia. Metropop bergenre romance ini terdiri dari 224 halaman, yang terbagi dalam 26 bab dengan prolog dan epilog. Almira Illini Bastari adalah penulis yang awalnya dikenal melalui platform Wattpad. Perempuan kelahiran 1990 di Illinois ini meraih gelar master di University of Melbourne. Ia telah bekerja sebagai analis keuangan namun hal itu tidak menyurutkan keinginannya menulis fiksi (Anindita, 2018). Selain Melbourne (Wedding) Marathon, novel-novelnya yang lain adalah Resign! (2018) dan Ganjil Genap (2020).

\section{Hasil dan Pembahasan}

\section{Narasi Percintaan dengan Latar Urban: Akhir yang Bahagia}

Kisah dalam novel Melbourne (Wedding) Marathon digerakkan terutama oleh protagonis perempuan yang bernama Sydney Deyanira, mahasiswa S2 bidang teknik yang kini berumur hampir 25 tahun. Ia tinggal serumah dengan Detira, seorang bangsawan Malaysia, dan Rafka, sahabat yang juga disukainya. Sydney cantik, cerdas dengan IQnya yang 138, mandiri, ambisius, dan perfeksionis. Ia merasa patah hati ketika Rafka memilih berpacaran dengan Clara. Meskipun tidak benar-benar menjalin hubungan, Sydney dan Rafka sempat menjadi sangat dekat dalam 
enam bulan sebelumnya. Yang Sydney ketahui, beberapa laki-laki yang pernah mendekatinya langsung mundur ketika melihat dirinya sebagai perempuan cerdas dan mandiri. Untuk mengisi waktu dan menambah uang jajannya, Sydney pun kerja paruh waktu memasak untuk Anantha Daniswara, seorang pengusaha sukses yang lajang.

Dalam keterpurukannya, Sydney pun tidak berpikir panjang ketika ditawari Anantha, untuk berpura-pura menjadi pacarnya selama tiga minggu demi menghindari pengejaran yang dilakukan Danisha, mantan kekasihnya. Sebagai upah atas jasa Sydney, Anantha membayarnya dengan cara menemani perempuan itu mendatangi tempat-tempat romantis di Melbourne.

Anantha seperti telah dipersiapkan oleh pengarang untuk menjadi the right person bagi Sydney, meskipun awalnya ia ditampilkan sebagai sosok yang arogan dan dingin pada perempuan. Ia tampan, sangat kaya raya, dan berasal dari keluarga Daniswara yang terpandang. Namun, ia bersedia berkompromi dengan Sydney agar gadis itu mau menjadi pacarnya selama tiga minggu. Mereka tidak boleh bersentuhan selama lebih dari 5 detik dan tidak boleh memberi tahu pihak lain tentang kontrak tersebut (hlm. 39). Namun kemudian hubungan mereka berkembang menjadi sungguhan, dimulai dari Anantha yang mengagumi kecantikan dan prinsip-prinsip Sydney yang awalnya tampak aneh baginya. Hubungan di antara mereka berbeda dengan antara Sydney dan Rafka. Di awal kisah diceritakan bahwa perempuan itu menyukai Rafka namun secara tiba-tiba, laki-laki ini meninggalkannya dan berpacaran dengan Carla, adik Danisha, yang merupakan mantan pacar Anantha.

Anantha, dengan segala privilese yang melekat padanya, berupaya menunjukkan perilaku kepahlawanan sebagai penciri the right person. Sekalipun dominan secara materi, ia tidak segan untuk mengambil alih peran feminin, di antaranya yaitu memasakkan makanan (spagheti) untuk Sydney yang sedang kelelahan. Anantha juga berkali-kali menawarkan untuk membelikan pakaian pesta untuk kekasih 'pura-puranya' itu, yang ditolak dengan tegas oleh Sydney.

Sebagai tokoh antagonis, ditampilkan Danisha (mantan pacar Anantha), Clara (adik Danisha, pacar Rafka), dan Pak Daniswara (kakek Anantha). Ketiganya datang dari keluargakeluarga yang sangat kaya. Gaya hidup modern dan konsumtif memang melatarbelakangi kehidupan sosial para tokoh yang digambarkan mapan secara finansial. Suasana pesta, mobil mewah (Porche, Range Rover, Lamborghini), serta merk-merk fashion terkenal dan mahal (Hermes, Gucci, Prada, Chanel) menunjukkan bagaimana dunia tempat tokoh Sydney, Anantha, dan teman-teman mereka berada. Untuk menguatkan kesan pentingnya nilai perkawinan, dalam novel tersebut ditampilkan serangkaian (marathon) pesta yang diselenggarakan di tempat-tempat megah, mulai dari pernikahan Oka di Palladium (hlm. 43), pertunangan Teddy di Southbank (hlm. 62), pernikahan Doddy di Grand Hyatt (hlm. 107).

Sebagai sebuah metropop, latar yang digunakan dalam novel Melbourne (Wedding) Marathon adalah ruang urban, bertempat di kota-kota besar dunia, mulai dari Jakarta, Melbourne, Singapura, Hongkong, Kuala Lumpur, hingga Tokyo. Sesuai dengan judul novel, Melbourne tentu menjadi kota yang dominan diceritakan, yang ditunjang dengan deskripsi tentang berbagai tempattempat romantis dan mendukung suasana percintaan, seperti Venice on the Yarra river (hlm. 49), Tram Restaurant (hlm. 86), Her Majesty Theatre (hlm. 91), dan tempat-tempat lain seperti Lupino, Kenzan, pertunjukan balet, Australia Open, dan New Zealand. 
Narator berada di luar kisah, sehingga sifat penceritaannya menjadi tidak terbatas dan ia dapat menyelami kedalaman hati para tokoh untuk kemudian menyampaikannya pada pembaca. Sudut pandang narator yang cenderung berkarakter feminin ini terungkap melalui keberpihakan narator kepada perempuan dan keputusannya menempatkan laki-laki sebagai Liyan, sebagaimana terlihat di dalam kutipan berikut ini.

Air muka Rafka tiba-tiba menjadi serius. "Lo marah, Syd?"

Peraturan pertama dalam menghadapi wanita yang mungkin Rafka belum tahu, jangan pernah menanyakan wanita apakah dia marah atau tidak. Bukannya mendapatkan kejujuran, yang ada wanita justru akan merasa semakin marah karena merasa pria sama sekali tidak merasa bersalah. (Bastari, 2017: 24)

Sebaliknya, sudut pandang laki-laki yang disampaikan melalui tokoh Rafka misalnya menjadi tidak menyenangkan dan terasa menjengkelkan [bagi perempuan]. Dalam kutipan berikut ini, Rafka menyarankan pada Sydney untuk tidak terlalu menjadi pemilih dan perfeksionis agar memiliki kekasih. "Wedding marathon? Tuh Syd, nggak usah straight H1 kalau mau dapat cowok, biar bisa posting juga punya pacar di Path," ujarnya sinis (Bastari, 2017: 14).

Dari sitasi tersebut, diketahui Rafka mempersepsi dan menyampaikan secara tidak langsung pada Sydney untuk 'menurunkan standarnya', bahwa tidak perlu menjadi perempuan yang sangat pintar (mendapat nilai H1/ sempurna) untuk mendapatkan seorang laki-laki. Tersirat pula stereotip tentang laki-laki yang tidak menyukai perempuan cerdas. Sydney terprovokasi ucapan-ucapan Rafka tentang umur dan karakternya sehingga sulit mendapatkan laki-laki yang sesuai. Sydney pun merasa patah hati ketika mendengar pernyataan Rafka bahwa ia berpacaran dengan perempuan lain bernama Carla, yang jauh lebih lembut dan manja dibandingkan dengan dirinya.

\section{Perkawinan dari Sudut Pandang Perempuan: Menolak Wacana Penguasaan}

Permasalahan utama yang dimunculkan dalam novel Melbourne (Wedding) Marathon adalah rangkaian pesta perkawinan/ pertunangan para teman yang harus dihadiri, baik oleh Sydney maupun Anantha. Ketiadaan partner pada kedua tokoh ini menautkan mereka menjadi pasangan pura-pura. Hal ini terjadi karena kenyataan datang sendiri ke sebuah pesta bukan merupakan situasi yang menyenangkan, dan kesendirian mereka berubah menjadi penderitaan dengan adanya eksposisi kebahagiaan yang ditampilkan pada media sosial.

Pernikahan, pertunangan, midodareni menghiasi Path setiap akhir minggu. Ia mengembuskan napas sambil tersenyum sinis. Hidup seharusnya sederhana, sampai sosial media berevolusi dan membuat manusia menjadi rentan akan tekanan. (Bastari, 2017: 2)

Kondisi yang dialami Sydney menyerupai penjelasan Septiana \& Syafiq (2013: 71), bahwa stigma kelajangan membuat perempuan dewasa yang belum menikah merasa tidak nyaman karena 'tidak laku', yang kemudian memengaruhi mentalitasnya menjadi tertekan dan kesepian. Ia 
terprovokasi oleh pernyataan Rafka dan undangan pernikahan dari teman-temannya yang membuatnya menyadari kesendiriannya yang tidak lagi menyenangkan.

Cara pandang masyarakat terhadap perempuan dan laki-laki lajang memang berbeda. Tokoh Sunny, yang tidak dimunculkan dalam cerita namun dijadikan sebagai ilustrasi oleh Rafka, merepresentasikan perempuan yang belum/tidak menikah, yang sekalipun mapan dan sukses dalam karier, namun tetap dianggap sebagai makhluk yang belum 'utuh' dan memiliki masalah dalam berhubungan sosial. Sementara itu, laki-laki dewasa yang belum/tidak menikah dianggap wajar karena dianggap sedang merintis dan menjalankan pekerjaannya.

Gue hanya nggak mau lo kayak Sunny. Empat puluh tahun, sukses, tapi single. Ingat, lo itu sudah mau 25, clock is ticking, tahu-tahu nanti kepala tiga susah cari jodoh. (Bastari, 2017: 12)

Sydney sebenarnya sudah letih dengan alarm yang dibunyikan oleh sekitarnya. Hampir separuh abad tampaknya adalah momok menakutkan bagi orang-orang tua, kakek, dan neneknya. Lalu 25 dan 26 adalah arus puncak pernikahan di mana Sabtu-Minggu bahkan bisa empat undangan pernikahan sekaligus. Pernikahan bukan lagi awal kehidupan, tapi seperti akhir pencapaian seorang wanita yang dapat dianggap 'sukses'. Buket bunga pengantin kini seolah-olah menjadi simbol kemenangan. (Bastari, 2017: 13)

Dalam novel, terdapat sekuen yang memaparkan Anantha mengetahui bahwa dirinya merupakan pacar pertama bagi Sydney. Situasi yang dianggap memalukan oleh perempuan itu dimanfaatkan oleh Anantha untuk mencandainya. Hal ini mengindikasikan perempuan dewasa yang belum menikah cenderung diposisikan dengan status identitas inferior karena dianggap tidak sesuai kewajaran atau 'tidak normal'.

“Akhirnya Sydney pecah telur juga, punya pacar pertama!” Detira menepukkan kedua tangannya sekali.

Anantha tersedak es batu, batuk-batuk, dan saat itu pula Sydney rasanya ingin ditelan bumi. Skak mat. End. Dia ingin membenturkan kepala di meja sekarang. [...]

“Jadi kamu belum pernah pacaran?” Anantha bertanya pada Sydney. (Bastari, 2017: 136)

Kutipan di atas merepresentasikan pandangan umum bahwa kelajangan adalah sebuah kategori sosial yang 'bermasalah', bahkan bagi mereka yang menempati posisi lajang itu sendiri. Secara dilematis, perempuan lajang menyikapi kondisinya. Di satu sisi, ada kebebasan, kemandirian, dan prestasi, namun di sisi lain, ada perasaan tertekan, kesepian, dan keinginan menuntaskan kelajangan tersebut. Perempuan pada umumnya memahami bahwa diperlukan ketelitian dan kehati-hatian dalam memilih calon pasangan, sehingga mereka merasa perlu menunda perkawinan (Septiana \& Syafiq, 2013: 72). Namun karena faktor lingkungan, keluarga, dan media sosial, perempuan dapat saja terpengaruh dan menjadi terburu-buru untuk segera menikah. Seperti diburu waktu, mereka pun didukung untuk menikah sesegera mungkin, karena 
secara biologis, semakin berumur, peluang mereka untuk mendapatkan pasangan juga dianggap semakin kecil.

"Aku kecewa, kenapa selalu gagal dengan orang lain. kenapa pria-pria itu selalu memilih orang lain, yang bahkan di atas kertas tidak lebih baik dari aku. Kenapa bagi Rafka aku selalu invisible, kenapa aku masih single di umur 24 tahun! I'm turning 25 soon." Sydney menjadi emosional.

"Banyak temanku yang akan menikah dan entah kenapa itu membuatku tertekan seolaholah aku akan kalah dalam suatu pertandingan yang bahkan tidak ada kompetisinya." Detira menatapnya kasihan. "Syd, sudah kubilang, jangan pikirkan apa yang ada di sekitarmu. Pernikahan itu bukan piala dan proses menuju ke sana bukan dengan sprint." (Bastari, 2017: 157)

Sebagai perempuan berpendirian keras, teratur, terencana, dan ambisius, Sydney dapat menjadi sangat rendah diri bila menyangkut hubungan. Kegalauan Sydney tersebut ditanggapi dengan bijak oleh Detira. Meskipun kondisinya sendiri tidak lebih baik daripada Sydney, namun Detira memiliki visi jelas tentang calon suaminya kelak. Ia harus dewasa dan dapat membimbing Detira sebagai istri. Sementara itu, dua laki-laki yang menyukai Sydney, Anantha dan Rafka, bersikap sebagai penjaga dan memperlihatkan adanya insekuritas atau sikap tidak nyaman mereka ketika perempuan itu berdandan dengan lebih mencolok. Mereka memperlihatkan posesivitas atas perempuan yang sebenarnya bukan merupakan pasangan mereka.

“Aku nggak suka lihat kamu pakai lipstik merah." [...]

Untuk kedua kalinya Anantha berkomentar setelah sebelumnya, di acara pernikahan Dody, Sydney mengabaikannya dengan pura-pura tidak mendengar. Ia tidak suka melihat kekasihnya yang selama ini terlihat seperti anak-anak, sekarang tampak sangat dewasa dan seksi.

“Kamu fashion police?” (Bastari, 2017: 91)

"Lo ngapain pakai lipstik merah, sih?" tanya Rafka. [...]

Dalam hati, ia kesal kenapa para pria yang dikenalnya hari ini sibuk berkomentar mengenai warna lipstiknya. Sejak kapan hal mikro begitu menjadi sesuatu yang sangat penting untuk dibahas?

"Lo kenapa pakai lipstik merah? Karena pergi sama Anantha?" tanyanya.

Sydney menoleh dengan pandangan sinis. "Gue pakai lipstik merah karena pakai baju ini. Nggak ada hubungannya sama Anantha!” (Bastari, 2017: 95)

Status lajang dan penampilan menarik pada seorang perempuan dapat menjadi godaan bagi laki-laki. Oleh karena itu, baik Rafka maupun Anantha merasa berkeberatan bila Sydney mengenakan lipstik merah yang diperkirakan akan menarik perhatian laki-laki pada umumnya.

Tania Intan: Isu Perkawinan Dan Kelas Sosial Dalam Metropop Melbourne (Wedding) Marathon Karya Almira Bastari: Kritik Sastra Feminis 
Namun, sebagai perempuan cerdas dan mandiri, Sydney tidak membiarkan wacana penguasaan oleh laki-laki berkembang atas dirinya. Ia menolak dikuasai Rafka dan Anantha.

Wacana seksualitas prapernikahan tidak dikembangkan dalam novel Melbourne (Wedding) Marathon, meskipun ada beberapa sekuen yang menampakkan hasrat Anantha pada Sydney. Namun batasan telah dibuat melalui surat kontrak dari hubungan pacaran pura-pura mereka, tidak boleh memeluk dan menyentuh lebih dari 5 detik. Sebagai laki-laki heteroseksual dewasa, secara tersirat maupun eksplisit, ia menunjukkan minatnya pada perempuan itu meskipun hal itu melanggar perjanjian di antara mereka. Pada beberapa kesempatan, Anantha melakukan pendekatan namun selalu ditolak oleh Sydney yang merasa belum siap.

Anantha membuka pintu dan sudah ada Detira yang hendak memencet bel di sana. Detira tampak tak percaya dengan matanya. Bagaimana mungkin ada Anantha di sana, dengan wajah kelelahan dan kancing teratas serta jasnya terbuka. Rambut Sydney juga berantakan. “Hi ... ergh ... guys?" Tangan Detira melambai dengan canggung. [..]

"Nan kita belum selesai ...," Sydney berusaha bicara namun Anantha memotong.

"We can do that after marriage, kalau sekarang kamu pregnant gimana?" Anantha mengedipkan mata dan membuat Sydney salah tingkah melihat Detira yang menganga sekarang. (Bastari, 2017: 213)

Namun, sebagaimana telah dijelaskan, Sydney tidak mudah ditaklukkan karena ia terbiasa mandiri dan tidak pernah memiliki pacar sebelumnya, sehingga berkesan kaku dalam menyikapi relasi percintaan tersebut. Perempuan ini pun tidak membiarkan laki-laki menguasai tubuhnya, selain karena prinsip keyakinan juga karena ia tidak terbiasa berada dalam suasana intim.

\section{Perkawinan dan Perbedaan Kelas Sosial}

Meskipun Sydney bukan seorang perempuan yang miskin, namun terdapat kesenjangan yang sangat lebar di antara dirinya dengan Anantha. Bahkan dalam lingkaran persahabatannya dengan Detira dan Rafka, Sydney berada pada posisi ekonomi paling lemah. Kondisi ini misalnya terlihat dari ketidakrelaannya saat harus membeli gaun pesta di sebuah butik ternama Australia.

Sydney bergegas menaiki tram menuju Mal Emporium di kota. Dia memasuki butik Zimmermann, salah satu designer Australia favoritnya yang sama sekali belum pernah ia beli. Dengan berat hati, ia ambil tuck dress lengan tiga perempat sepanjang lutut yang berwarna putih dengan motif dedaunan hitam. Ia sama sekali tidak ingin melihat ketika kartunya digesek. Belum pernah seumur hidup, ia membeli baju seharga hampir seribu dolar. Baju belum dimasukkan ke dalam plastik, ia sudah berpikir untuk menjualnya agar tidak terlalu merasa rugi. (Bastari, 2017: 41)

Meskipun ia juga menyukai Anantha, Sydney tahu diri bahwa dirinya tidak sebanding dalam konteks sosial-ekonomi dengan laki-laki itu. "I can't afford your lifestyle. Apa kamu nggak malu sama bawa pacar yang beda kastanya sama kamu? "(hlm. 83). Perempuan ini pun dengan 
tegas menolak tawaran Anantha yang hendak membelikannya gaun-gaun pesta. Sydney tidak ingin menerima apa pun dari laki-laki itu karena sekali saja ia bersedia, maka nilai harga dirinya turun drastis dan dirinya menjadi inferior. Selain itu, Sydney tidak benar-benar miskin karena ia masih dapat membeli tas Coach dan sepatu Michael Kors.

[...] ia sudah tahu apa yang menjadi takdirnya dan Anantha. Terutama setelah ia pergi ke semua pesta teman-teman Anantha. Ia tidak mungkin berada di golongan sosial itu. Sebenarnya, ia tidak pernah merasa seperti orang miskin, karena ia tidak miskin. Tapi jelas ia bukan orang bisa dengan mudah menggelontorkan uang hanya untuk beli sendal jepit Hermes seperti yang dipakai Clara di Lupino. (Bastari, 2017: 120)

Hambatan dalam relasi Sydney dan Anantha datang dari para tokoh antagonis, yaitu Danisha, Clara, dan Pak Daniswara. Kakek Anantha itu sampai memanggil Sydney ke kantor untuk menyuapnya dengan mobil, apartemen, dan uang, agar meninggalkan sang cucu. Sydney merasa sakit hati namun dapat memahami ketika laki-laki kaya raya, berkuasa, dan sering masuk majalah bisnis itu mengutarakan maksud dan menggunakan istilah "orang dari level kayak kamu" (hlm. 180) yang merujuk pada dirinya. Namun, Sydney menolak wacana penguasaan yang hendak ditimpakan padanya, dan menyatakan dengan tegas bahwa ia memang akan meninggalkan Anantha.

Tidak ada yang salah dari wanita-wanita yang dipilih oleh putra dan cucunya. Mereka semua datang dari keluarga berada, berpendidikan, dan tidak buruk, namun itu tidak cukup baginya. Perempuan yang bisa menjadi pendamping keturunan Daniswara harus yang satu tingkat dengan mereka, yang mampu memberikan dukungan dari segi materiil dan immateriil. Bukan manusia-manusia yang nantinya hanya bisa berdoa ketika grup yang dirintis sejak zaman ayahnya itu berada di ujung tanduk. (Bastari, 2017: 181)

Selain ditentukan oleh strata sosial dan latar belakang keluarga, perkawinan juga menautkan dua pihak yang [seharusnya] setara secara status, yaitu sama-sama lajang. Dalam konteks novel Melbourne (Wedding) Marathon, meskipun Danisha berasal dari keluarga yang kaya raya, ia dianggap tidak dapat menikah dengan Anantha karena pernah menikah. Untuk menghindari konflik di kemudian hari, status sosial perempuan tidak luput dari perhatian keluarga laki-laki.

"Kakek nggak akan ngizinin aku menikah dengan divorcee." Anantha menyeruput kopinya lagi.

“Kamu pikir aku sampah?!” Intonasi Danisha naik. (Bastari, 2017: 192)

Dengan memiliki status sosial yang lebih tinggi, yang ditunjukkan dengan kekayaan dan kekuasaan yang melimpah, Anantha dan keluarganya merasa memiliki hak untuk mengambil keputusan tentang sosok pendampingnya. Ia tampil percaya diri dan dominan di hadapan orang 
lain, tapi bersedia [sedikit] merendahkan diri pada perempuan yang dicintainya. Anantha juga melakukan pembelaan atas hubungannya dengan Sydney pada sang kakek sehingga akhirnya mereka pun direstui untuk menikah. Meskipun merasa cukup dengan dirinya, kehadiran Anantha, laki-laki yang ia cintai, membuat Sydney kini merasa dirinya telah utuh.

\section{Simpulan}

Hasil penelitian menunjukkan bahwa novel Melbourne (Wedding) Marathon karya Almira Bastari sesuai dengan kriteria metropop, seluruh elemen naratif dalam novel yang dikaji mendukung ide tentang percintaan dan perkawinan dengan latar urban. Sekalipun berada dalam situasi modern dan berkarakter mandiri, perkawinan masih didambakan oleh tokoh perempuan dengan harapan menjadi lembaga yang mengusung kesetaraan gender. Isu kelas menjadi hambatan dalam relasi percintaan tersebut namun dapat diatasi berkat penolakan tokoh perempuan atas wacana penguasaan.

Ketergesa-gesaan perempuan untuk memasuki dunia perkawinan yang terungkap dalam novel Melbourne (Wedding) Marathon disebabkan oleh ancaman atas identitas sosial lajangnya, yang diposisikan masyarakat lebih inferior dibandingkan dengan status menikah. Masih ada celah yang dapat dilakukan untuk penelitian selanjutnya, misalnya dengan menggunakan pendekatan sosiologi sastra dan kajian budaya. Meskipun tema-tema yang diangkat, yaitu ketergesa-gesaan perempuan untuk menikah, hubungan pura-pura, dan kesenjangan sosial, merupakan gagasan yang berulang dan tipika khas romance, namun secara umum, Almira Bastari dapat menyajikan novel tersebut dengan baik dan menarik.

\section{Daftar Pustaka}

Adji, M., Rahayu, L.M., Banita, B. 2009. Perempuan dalam Kuasa Patriarki. Laporan Penelitian. Fakultas Sastra Universitas Padjadjaran. Jatinangor.

Anggraini, M. \& Hayati, Y. 2019. Potret Masyarakat Urban dalam Novel Resign! Karya Almira Bastari. Jurnal Bahasa dan Sastra. 7 (2). 1-6.

Anindita, Meutia Ersa. 2018. Almira Bastari: Dulu Dicitakan, Sekarang Dinyatakan. https://www.gramedia.com/blog/perjalanan-karir-almira-bastari-penulis-buku-best-sellerdari-wattpad/ diakses tanggal 2 Agustus 2020.

Bastari, Almira. 2017. Melbourne Wedding Marathon. Jakarta: PT Gramedia Widiasarana Indonesia.

Conley, T.D., \& Collins, B.E. 2002. Gender, Relationship status, and Stereotyping about Sexual Risk. Personality and Social Psychology Bulletin. 28. 1438-1494.

Djajanegara, S. (2003). Kritik Sastra Feminis: Sebuah Pengantar. Jakarta: PT Gramedia Pustaka Utama.

Fahmi, R.F. \& Arfiyanti, R. 2020. Kesetaraan Perempuan dan Polemik Budaya Patriarkal dalam Novel Cinta Suci Zahrana. Deiksis. Vol. 7 (1). 36-45.

Fitriana, Adytia. 2010. Karakteristik Novel-novel Metropop Gramedia. Skripsi. Universitas Indonesia. Depok. 
Heise, Franka. 2012. "I'm a Modern Bride": On the Relationship between Marital Hegemony, Bridal Fictions, and Postfeminism. Journal Media Culture. 15 (6). http://www.journal.media-culture.org.au/index.php/mcjournal/article/view/573 diakses tanggal 1 Agustus 2020.

Humm, Maggie. 2007. Ensiklopedia Feminisme. Yogyakarta: Fajar Pustaka Baru.

Intan, T., Handayani, V.T., Som, W.S. (2019). Citra Perempuan dalam Novel Metropop Tetralogi Empat Musim Karya Ilana Tan. Nusa. 14 (4). 583-598.

Kumalasari, D. 2007. Single Professional Women Sebagai Fenomena Gaya Hidup Baru di Masyarakat Yogyakarta (Studi Kasus: Kabupaten Sleman). Laporan Penelitian. Universitas Negeri Yogyakarta. Yogyakarta.

Mami, Lutfita \& Suharnan. 2015. Harga Diri, Dukungan Sosial, dan Psychological Well Being Perempuan Dewasa yang Masih Lajang. Persona, Jurnal Psikologi Indonesia. Vol. 4 (3). 216-224.

Priyatna, A. 2018. Kajian Budaya Feminis Tubuh, Sastra, dan Budaya Pop. Yogyakarta: Arti Bumi Intaran.

Putri, D. P. K. \& Lestari, S. 2015. Pembagian Peran Dalam Rumah Tangga Pada Pasangan Suami Istri Jawa. Jurnal Penelitian Humaniora. 16 (1). 72-85.

Septiana, E. \& Syafiq, M. 2013. Identitas Lajang (Single Identity) dan Stigma: Studi Fenomenologi Perempuan Lajang di Surabaya. Jurnal Psikologi Teori dan Terapan. 4 (1) 71-86.

Umar, Nasaruddin. 1999. Argumen Kesetaraan Jender Perspektif Al-Quran. Jakarta: Paramadina. Wiyatmi. (2012). Kritik Sastra Feminis: Teori dan Aplikasinya dalam Sastra. Yogyakarta: Ombak. 